Neither has yet been shown to be appreciably better than the other.

Once established, a best documented practice could be displaced only if rigorous tests showed that a different treatment was better. Information on the effects of a best documented practice on patients could be easily stored on computer, providing a standard for internal audit. Any change in response rates or other outcomes should become apparent early. Questions might be asked close to the source of the information, which would provide substantially more reliable data than are currently available in most hospitals for most patients. To some, such scrutiny may suggest a loss of clinical freedom. As resources are limited and always will be, however, a consensus on best documented practice may help doctors decide how best to use those resources at their disposal.

Several royal colleges have endorsed medical audit, regarding it as an integral part of modern clinical practice. ${ }^{3}$ The government's new white paper Working for Patients supports their view. ${ }^{+}$To audit satisfactorily an idea is needed not only of outcome but also of the appropriateness of treatment. Audit would be substantially simplified by establishing a best documented practice for each clinical condition. One problem of recognising a best documented practice would be the legal implications of establishing a standard. The threat is perhaps greatest to the spurious or untested remedy.

Optimum management must always remain under challenge from new developments, and one best documented practice will be replaced when the benefits of another have been shown. Recognising a best documented practice is no substitute for clinical skills-it permits, however, the channelling of those skills for the best advantage of those for whom they are intended: the patient.

Professor,

J M A WHITEHOUSE

CRC Wessex Regional Medical Oncology Unit,

Southampton General Hospital,

Southampton SO9 4XY

1 Gruppo Internationale Cooperativo Oncologico Ginecologia. Randomised comparison of cisplatin with cyclophosphamide/cisplatin and with cyclophosphamide/doxorubicin/cisplatin in advanced ovarian cancer. Lancet 1987;i:353-9.

2 Anonymous. Proceedings of the NIH concensus development conference on adjuvant chemotherapy and endacrine therapy for breast cancer. Washington: National Cancer Institute, 1986:1-4. (National Cancer Institute moneraph

3 Royal College of Physicians. Medical audit - a first report. London: Royal College of Physicians, 1989. 4 Secretaries of State for Health, Wales, Northern Ireland, and Scotland. Working for patients. London: HMSO, 1989. (Cmnd 555.)

\title{
Treatment of shingles and post-herpetic neuralgia
}

\author{
Relieves shingles but does not prevent neuralgia
}

The annual incidence of herpes zoster in the general population ranges from an estimated 0.8 to 4.8 per thousand. ${ }^{1-3}$ Nevertheless, this increases sharply with age-from two to three cases per 1000 in early adult life to five in the sixth decade, six to seven in the seventh and eighth decades, and 10.1 in those aged 80 and over - corresponding to the natural decline in cell mediated immunity. ${ }^{12}$

Herpes zoster occurs spontaneously in normal people, most cases being self limiting and resolving completely. ${ }^{2+}$ The pain may be severe but is usually transitory; but increasing age increases both the duration and severity of herpes zoster neuralgia. ' Complications occur in $15-20 \%$ of cases, the most common being post-herpetic neuralgia in $9-14 \% .^{+}$This is pain persisting or occurring at the site of shingles over 30 days after the onset of the acute infection. ${ }^{56}$ Its frequency and severity increase with age; it occurs in $16 \%$ of patients under 60 and $47 \%$ of those over $60 .{ }^{1}$ In one study no fewer than three quarters of patients over 70 had post-herpetic neuralgia, and one year after the acute infection it persisted in $42 \%$ of those aged under 20 and about half of those over $70 .{ }^{7}$ Herpes zoster of the eye is a complication in $2 \%$ of cases, being associated with a high rate of inflammatory and neuropathic occular complications in half to three quarters of instances; such complications, especially keratitis and uveitis, may become chronic, sometimes causing loss of vision. ${ }^{8}$

The treatment of acute herpes zoster aims at reducing the upset caused by the acute infection as well as preventing complications, especially post-herpetic neuralgia. The results of studies on the efficacy of topical idoxuridine in dimethyl sulphoxide in uncomplicated herpes zoster are difficult to assess because the control groups were not always closely matched. ${ }^{9}$ In one study $40 \%$ idoxuridine applied continuously to cover the whole of the dermatome relieved the pain ${ }^{10}$; in another study it had no effect on the pain; but the inflammatory response was shortened. ${ }^{\text {"N }}$ Neither healing nor pain were altered in thoracic herpes zoster whereas both were greatly improved in trigeminal infection. ${ }^{12}$

Hence questionable efficacy as well as the side effects and the cost limit the usefulness of idoxuridine. In immunocompetent patients, on the other hand, herpes zoster may be severe enough to warrant antiviral treatment, particularly in the elderly. Acyclovir has largely replaced idoxuridine and older antiviral agents because of its low toxicity and ease of administration. ${ }^{13}$ Oral acyclovir given in high dosage $(800 \mathrm{mg}$ five times daily for seven days) early in the illness modifies the rash and reduces pain. ${ }^{14}$ It does not, however, diminish the likelihood of neuralgia, either by itself ${ }^{516}$ or with prednisolone, ${ }^{15}$ though it will lessen the more common occular complications, including keratitis and uveitis. ${ }^{8}$ Treatment is expensive and thus can be considered only in patients presenting with acutely painful shingles within 48 hours of the onset of the rash, immunocompromised patients, and those with herpes zoster of the eye.

Multiple and repeated sympathetic and somatic nerve blocks relieve the pain of acute shingles and are valuable in preventing subsequent neuralgia. Early treatment of acute shingles at a pain clinic by sympathetic blockage and infiltration of somatic nerve endings with local anaesthetics has been suggested to prevent the development of postherpetic neuralgia, ${ }^{17} 18$ but in view of the frequency of the condition this can be offered only to those at greatest risk, to the elderly, or to immunocompromised patients with severe acute infection.

Corticosteroids are commonly used to prevent the development of neuralgia despite conflicting results of several studies. ${ }^{19-21}$ Further research is needed before this treatment can be recommended, given its immunosuppressive effects and potential for serious complications. In a small, poorly controlled study amantadine given twice daily to patients with acute herpes zoster had no effect on the acute illness 
but reduced the proportion of patients with prolonged post-herpetic neuralgia. ${ }^{22}$ Many other reports have dealt with various treatments, but these all need evaluating by controlled studies. ' Clinical experience suggests that systemic analgesics, either non-steroidal anti-inflammatory drugs or an opioid drug, may moderate the acute pain in herpes zoster, but evaluations of their efficacy have not been reported. Conventional analgesics are ineffective in managing the neurogenic pain, and the most efficacious treatment is probably prolonged treatment with anticonvulsants and tricyclic agents. ${ }^{1722-25}$ Baclofen may have a therapeutic role in controlling the pain, ${ }^{26}{ }^{27}$ and an epidural injection of steroids is efficacious to the extent that it may be the best treatment for chronic intractable neuralgia when steroids are not contraindicated..$^{28}$ Acupuncture $^{29}$ and transcutaneous stimulation ${ }^{30} 31$ are other possibly effective adjuvant treatments. Finally, preliminary results suggest that topical capsicum, a neuropeptide active agent, may have an important therapeutic role in post-herpetic neuralgia..$^{32} 33$

Principal in General Practice,

JACQUELINE V JOLLEYS

Belton,

Nr Loughborough,

Leicestershire LE12 9UJ

1 Russell K, Portenoy RK, Duma C, Foley KM. Acute herpetic and post herpetic neuralgia: clinical review and current management. Ann Neurol 1986;20:651-61.

2 Hope-Simpson RE. The nature of herpes zoster: a long term study and a new hypothesis. Hope-Simpson RE. The nature of herpes zoster: a long
Proceedings of the Royal Society of Medicine 1965;58:9-20.

Proceedings of the Royal Soclety of Medicine 1965;58:9-20.
Kurtzke J. Neuroepidemiology. Ann Neurol 1984;16:265-77.

4 Ragazzino MW, Melton LJ III, Kurland LT, Chu CP, Perry HO. Population-based study of herpes zoster and its sequelae. Medicine 1982;61:310-6.

5 Hope-Simpson RE. Post herpetic neuralgia. $\mathcal{J} R$ Coll Gen Pract 1975;26:571-5.

6 Loeser J. Herpes zoster and post herpetic neuralgia. Pain 1986;25:149-64.
7 Demorgas JM, Kierland RR. The outcome of patients with herpes zoster. Arch Dermutol 1957;75:193-6

Cobo M. Reduction in the occular complications of herpes zoster ophthalmicus by oral acyclovir Am F Med 1988;85:90-3.

9 Nicholson KG. Antiviral agents in clinical practice. Lancet 1984;ii:677-82.

10 Juel-Jensen BE, MacCullum F, MacKenzie A. Treatment of zoster with idoxuridine in dimethyl sulphoxide. Results of two double blind trials. Br Med J 1970;iv:776-80.

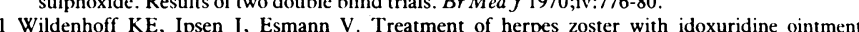
including a multivariate analysis of symptoms and signs. Scand I Infect Dis 1979;11:1-9.

Esmann V, Wildenhoff KE. Idoxuridine in herpes zoster. Lancet 1980;ii:474.

13 Peterslund NA. Management of varicella zoster infections in immunocompetent hosts. Am $7 \mathrm{Med}$ 1988;85:74-8.

14 McKenzie MW, McGill J, White J, Wood MJ. Oral acyclovir in acute herpes zoster. Br. Med $\mathcal{J}$ 1986;293:1529-32.

15 McKendrick MW, McGill JI, Wood MJ. Lack of effect of acyclovir on post herpetic neuralgia. BrMed f 1989;298:431.

16 Wood MJ, Ogan PH, McKendrick MW, Care CD, McGill JI, Webb EM. Efficacy of oral acyclovir in treatment of acute herpes zoster. Am $\mathcal{F}$ Med 1988;85:79-83.

17 Bhala BB, Ramamoorthy C, Bowsher D, Yelnoorker KN. Shingles and post herpetic neuralgia. Clinical Journal of Pain 1988;4:169-74.

18 Keczkes K, Busheer AM. Do corticosteroids prevent post herpetic neuralgia? Br f Dermatol $1980: 102 \cdot 551.5$

19 Esmann V, Geil JP, Kroon S. Prednisolone does not prevent post herpetic neuralgia. Lancet 977;ii:126-9.

20 Post BT Philbrick J. Do corticosteroids prevent post herpetic neuralgia? A review of the evidence. 7 Am Acad Dermatol 1988;18:605-10

21 Galbraith AW. Treatment of acute herpes zoster with amantadine hydrochloride (Symmetrel). Br Med f 1973;iv:693-5.

22 Thompson $M$, Bones $M$. Non traditional analgesics for the management of post herpetic neuralgia. Clin Pharm 1985; 4:170-6.

23 Watson CP, Evans RJ, Reed K, Merskey H, Goldsmith L, Warsh J. Amitriptyline versus placebo in post herpetic neuralgia. Neurology 1982;32:671-3.

24 Clarke IM. Amitriptyline and perphenazine in chronic pain. Anaesthesia 1986;36:210-2.

25 Max MB, Schafer SC, Culnane M, Smoller B, Dubner R, Gracely RH. Amitriptyline but not lorazepam relieves post herpetic neuralgia. Neurology 1988;38:1427-32.

26 Steordo L, Leo A, Marano E. Efficacy of baclofen in trigeminal neuralgia and other painful conditions: a clinical trial. Eur Neurol 1984;23:51-5.

27 Terrence CF, Fromm GH, Tenicela R. Baclofen as an analgesic in chronic peripheral nerve disease. Eur Neurol 1985;24:380-5.

28 Forrest JB. The response to epidural steroid injections in chronic dorsal root pain. Canadian Anaesthetists' Society fournal 1980;27:40-6.

99 Spourel WE Varkey M, Leung CY Acupuncture in chronic pain. Am f Clin Med 1976;4:267-79.

30 Lang DM. Stimulation of the peripheral nervous system for pain control. Clin Neurosurg 1983;31:323-43.

31 Thorsteinsson G. Chronic pain: use of TENS in the elderly. Geriatrics 1987;42:75-86.

32 Bernstein JE, Bickers DR, Dahl MV, Roshal JY. Treatment of chronic post herpetic neuralgia with topical capsaicin. A preliminary study. I Am Acad Dermatol 1987;17:93-6.

33 Bernstein JE. Capsaicin in the treatment of dermatologic disease. Cutis 1987;39:352-3.

\section{Radioactive patients}

\section{Patients given radioactive substances represent a small risk to others}

Patients given radioactive substances become sources of radioactivity and present a hazard to those with whom they come into contact. Most patients given radioactive substances present only a small risk to others, but guidance needs to be followed carefully to ensure that the risk is kept to a minimum - particularly in the case of those given radiolabelled iodine (iodine-131) therapeutically.

Radiotherapy with sealed radioactive sources is carried out in designated centres on inpatients under controlled conditions of isolation, and the patients are not discharged until the treatment has been completed and the sources have been removed. On the other hand, unsealed radioactive sources are used more commonly in more hospitals, for diagnosis as well as for treatment, and in outpatients as well as inpatients. These procedures result in patients becoming mobile sources of radiation, presenting two distinct types of hazard. Firstly, radiation is emitted from the patient, so that members of the public, porters, nurses, and other hospital staff are exposed. Secondly, specimens of the patient's tissue and body fluids such as blood and urine may become radioactive, presenting a risk to family members and other people at home and to people in hospital wards, operating theatres, and the mortuary.

The doses of radioactivity used in diagnostic tests are specified by the Administration of Radioactive Substances Advisory Committee, which issues the licence necessary for consultants to give radioactive substances to patients. ' Doses exceeding the specified values are given only in special circumstances. Most unsealed radioactivity used diagnostically is in the form of a radiopharmaceutical containing $99^{\mathrm{m}} \mathrm{Tc}$, and its physical half life of six hours means that the radiation hazard is short lived. Special precautions may be necessary only when prolonged close contact with another subject is unavoidable or when there is a risk of contamination. The risk of close contact is greatest when a patient is caring for an infant at home. It may be identified by questioning the patient and minimised by issuing explicit instructions. The risk of contamination will be greatly reduced by following simple principles of hygiene and by adopting the protective measures routinely used for handling biological material.

By far the greatest hazard comes from giving iodine-131 therapeutically. Radioiodide is secreted in body fluids such as sweat and saliva, and more stringent precautions must be taken against both contamination and close contact. Conventional doses for treating thyrotoxicosis are normally given to outpatients, but the higher doses given for thyroid carcinoma mean that patients have to remain in hospital nursed under conditions of isolation similar to those that apply to treatments from sealed sources. If radioactivity retained by the patient when leaving hospital exceeds certain defined amounts then the method of transport will be restricted and an instruction card must be issued to minimise the dose to others, particularly young children.

Statutory control is provided by the Ionising Radiations Regulations $1985,{ }^{2}$ and their interpretation for clinical appli- 